\title{
ENDOSONOGRAPHY VERSUS ENDOSCOPIC RETROGRADE CHOLANGIOPANCREATOGRAPHY IN DIAGNOSING EXTRAHEPATIC BILIARY OBSTRUCTION
}

\author{
Igor Tozzi di Angelo**, Vlastimil Prochazka ${ }^{a}$, Martin Holinka ${ }^{a}$, Jana Zapletalova ${ }^{\mathrm{b}}$
}

\author{
a Department of Internal Medicine II - Gastroenterology and Hepatology, University Hospital Olomouc, Czech Republic \\ ${ }^{b}$ Department of Medical Biophysics, Faculty of Medicine and Dentistry, Palacky University Olomouc \\ E-mail:igor.tozzi@fnol.cz
}

Received: April 6, 2011; Accepted: July 15, 2011; Available online: September 5, 2011

Key words: Radial endosonography/Endoscopic retrograde cholangiopancreatography/Transabdominal ultrasonography/ Choledocholithiasis

Objective. Endosonography (EUS) performed prior to endoscopic retrograde cholangiopancreatography (ERCP) or surgery in patients with a low to moderate probability of choledocholithiasis can reduce morbidity, mortality and costs.

Aims. This study aimed at evaluating the sensitivity and specificity of EUS and transabdominal ultrasonography (TUS) compared to ERCP in a cohort of 100 patients diagnosed with extrahepatic biliary obstruction.

Methods. There were four working groups. The first group processed the initial data including history, physical examination and assessment of laboratory markers of cholestasis. The second group examined TUS. The third group examined the pancreas and biliary tree using EUS, always prior to ERCP. The fourth working group carried out ERCP.

Results. The sensitivity and accuracy of EUS in the diagnosis of common bile duct dilatation were $84 \%$ and $83 \%$, respectively, i.e. significantly higher ( $\mathrm{p}=0.0001)$ than TUS ( $46 \%$ and $66 \%$, respectively). The specificities of methods $(82 \%, 91 \%)$ were not significantly different $(\mathrm{p}=0.218)$. The sensitivity and accuracy of EUS in the diagnosis of pathological content of the common bile duct were $88 \%$ and $92 \%$, respectively, i.e. significantly higher $(\mathrm{p}<0.0001)$ than TUS (33\% and 64\%). The specificities of the methods $(96 \%, 94 \%)$ were not significantly different $(\mathrm{p}=0.641)$.

The incidence of choledocholithiasis in the high-risk group was significantly higher than in the moderate-risk group $(\mathrm{p}=0.012)$.

Conclusion. Radial EUS is a method with high sensitivity, specificity, positive and negative predictive values. It should therefore be preferred to ERCP in patients with low or moderate risk of choledocholithiasis.

\section{INTRODUCTION}

Radial endosonography (EUS) combines two modalities, endoscopic visualization and high-frequency ultrasound, thus providing an advantage over other imaging techniques when showing the individual layers of the gastrointestinal tract.

Choledocholithiasis, the presence of gallstones in the common bile duct, is a common biliary tract disease. The symptoms may include biliary colic, jaundice and itching, including complications such as cholangitis or acute biliary pancreatitis.

When suspecting choledocholithiasis, the initial diagnostic method used is transabdominal ultrasonography (TUS), beneficial for its wide availability, noninvasiveness, absence of radiation and low costs. However, TUS is capable of complete visualization of the extrahepatic bile duct in only $60-80 \%$ (ref. $^{1,2}$ ). Moreover, clinical studies have suggested low sensitivity (25-82\%) and limited specificity (56-100\%) of TUS when detecting bile duct stones ${ }^{2-6}$. It's reported positive and negative predictive values are $69 \%$ and $78 \%$, respectively ${ }^{7}$. The wide ranges of percentage may be partly explained by its dependence on the investigator's practical skills and experience.
Endoscopic retrograde cholangiopancreatography (ERCP) is one of the gold standards in the diagnosis and treatment of bile duct stones. ERCP is invasive method which can cause complications in $3-6 \%$ of cases $^{8-10}$ or in as many as $5.3-6.5 \%$ of cases following papilla sphincterotomy ${ }^{11}$. Potential complications include acute pancreatitis, perforation, bleeding or sepsis, with lethal complications being present in $0.1-1.3 \%$ of cases ${ }^{12-16}$. Such a risk is unacceptable for patients with low to moderate probability of bile duct stones. The advantages of ERCP are the possibility of performing sphincterotomy and basket or balloon extraction of bile duct stones. On the other hand, a small stone may be missed in the very dilated common bile duct. According to the available literature, the sensitivity and specificity of ERCP in detecting choledocholithiasis are $79-93 \%$ and $92-100 \%$, respectively ${ }^{3,17-21}$.

Although EUS is also investigator-dependent, it is unparalleled for the intimate relation between the ultrasound probe and the investigated area. In a large number of studies published, the sensitivity and specificity of EUS in detecting bile duct stones were found to be $88-97 \%$ and 93-100\%, respectively ${ }^{2,18-24}$.

As the ultrasound probe is only $1-2 \mathrm{~cm}$ far from the bile duct, very detailed images are possible. This, together 
with safety and absent radiation, makes endosonography an excellent method for examining the bile duct and gall bladder. Using EUS, small stones, bile sludge and even microlithiasis may be detected. In most cases, choledocholithiasis may be identified as round linear hyperechoic structures with distinctive acoustic shadows.

The extrahepatic bile duct may be completely visualized by EUS in $96 \%$ (ref. $^{2}$ ). EUS is a minimally invasive procedure, especially beneficial in patients with low to high probability of stones detected in the bile duct ${ }^{25}$. In such cases, it should be used as the method of choice to ERCP or bile duct exploration surgery (either open or laparoscopic) which may increase the risks, morbidity and patient costs.

Our aim was to study a group of 100 patients diagnosed with extrahepatic biliary obstruction to assess the benefits and accuracy of radial endosonography in comparison with transabdominal ultrasonography and ERCP.

\section{MATERIAL AND METHODS}

Between May 2006 and March 2008, a total of 100 patients were enrolled in the study, 49 males (49\%) a 51 females $(51 \%)$ aged 31 to 87 years (mean age $63 \pm 13$ ). Of those, 31 patients underwent cholecystectomy. The patients were investigated according to an algorithm approved prior to the study. All patients signed informed consent to all the planned diagnostic procedures.

Patients suspected of having bile duct obstruction were included in the study based on their history, physical examination and laboratory test results. They were divided into two main groups: icteric or anicteric cholestasis.

The study was carried out by 4 working groups, with one experienced physician in each. The first group processed the initial data including history, physical examination and assessment of laboratory markers of cholestasis (gamma-glutamyl transferase, alkaline phosphatase - ALP, total bilirubin, direct bilirubin, alanine aminotransferase / ALT/ and aspartate aminotransferase levels /AST/).

The second working group used standard transabdominal ultrasonography to examine patients who met the criterion of at least six hours of fasting. TUS was performed using the Aloka ProSound SSD Alpha 5 ultrasound system. The sonographer tried to obtain as accurate an image of the entire bile duct as possible, measure its diameter with a cursor, detect heterogeneity of the common bile duct content, visualize the gallbladder, hepatic hilum and head of the pancreas.

The third group examined the pancreas and biliary tree using radial endosonography, always prior to ERCP. There was no exact time interval between the two procedures carried out during a single session within $24 \mathrm{~h}$ except for weekends. Patients who failed to meet the criteria were excluded. The EUS investigation was performed with the Olympus GF-UM 160 system using frequencies of 5, 7.5, 12 and $20 \mathrm{MHz}$. Once again, patients had to fast for at least $6 \mathrm{~h}$ before the procedure. According to their immediate clinical condition, the patients were pre-treated with singledose midazolam (1-3 mg IV) and butylscopolamine (20 mg
IV). During EUS investigation, the duodenum and radial EUS probe balloon were instilled with gas-free water to obtain as clear an ultrasound image as possible. The common bile duct was investigated from two basic positions. In the first - apical - position, the EUS probe is located at the apex of the duodenal bulb. The second position, from the region of the papilla of Vater, enables examination of a larger portion of the common bile duct. When interpreting EUS images, the common bile duct diameter was measured with a cursor in its proximal and distal halves, the presence of heterogeneous contents in the common bile duct was assessed and the condition of the papilla of Vater was determined. The head of the pancreas was examined from the apex of the duodenal bulb, from the region in the descending duodenum opposite the papilla of Vater and distally from the region below the papilla of Vater.

The fourth working group carried out ERCP with the Olympus TJF - $160 \mathrm{R}$ duodenoscope within $24 \mathrm{~h}$ of the patients' admission to our department. Prior to ERCP, blood count, coagulation parameters (INR and aPTT) and biochemical test results were available, and none of the patients had undergone ERCP with papilla sphincterotomy in the past. As in the case of EUS, patients were premedicated (midazolam IV, butylscopolamine IV). The papilla of Vater was cannulated using a wire-guided papillotome. Cholangiography of the extrahepatic and intrahepatic bile ducts was performed using the Telebrix 300 meglumine iodinated contrast medium. In five patients with a history of allergy, Omnipaque, a nonionic, monomeric, tri-iodinated water-soluble radiographic contrast agent, was used instead. All patients had their bile duct inspected with a Dormia basket or balloon. No cases required either duodenal biliary or nasobiliary drainage.

Following ERCP, the investigated and treated patients were hospitalized at our department, in both the normal ward and, if necessary, the intensive care unit.

The likelihood of choledocholithiasis was evaluated using clinical, laboratory and radiographic criteria. The low-risk group comprised patients with normal liver test results, a bile duct diameter of $\leq 7 \mathrm{~mm}$ and no history of cholecystolithiasis. The moderate risk of detection of choledocholithiasis was in patients with a history of acute cholangitis or biliary pancreatitis and/or recorded increased liver test values and/or present bile duct dilatation of $8-10 \mathrm{~mm}$. The high-risk group included patients with a recent history of an episode of acute cholangitis or pancreatitis, jaundice or more than double increase in ALP and/or bile duct dilatation of $\geq 11 \mathrm{~mm}$. Subsequently, the groups were followed to detect the actual presence of bile duct stones using TUS, EUS and/or ERCP.

ERCP was established as the gold standard for examining the extrahepatic bile duct. The common bile duct was considered dilated if the largest diameter exceeded $6 \mathrm{~mm}$ in patients both with and without previous cholecystectomy. Positive pathological findings in the common bile duct included macro- and microlithiasis as well as bile sludge. The results were statistically processed at the Department of Medical Biophysics, Palacký University in Olomouc with the Statistica CZ 6.0 software and a statistical significance level of 0.05 . 

extrahepatic biliary obstruction

Table 1. Statistical comparison of TUS and EUS for diagnosing extrahepatic bile duct dilatation.

\begin{tabular}{|l|c|c|c|c|c|}
\hline & TUS & $\begin{array}{c}95 \% \text { confidence } \\
\text { interval }\end{array}$ & EUS & $\begin{array}{c}95 \% \text { confidence } \\
\text { interval }\end{array}$ & $\begin{array}{c}\text { Statistical } \\
\text { significance }\end{array}$ \\
\hline Sensitivity & $45.5 \%$ & $38.0-49.7 \%$ & $83.6 \%$ & $75.9-89.2 \%$ & $\mathrm{p}=0.0001$ \\
\hline Specificity & $91.1 \%$ & $82.0-96.3 \%$ & $82.2 \%$ & $72.8-89.0 \%$ & $\mathrm{p}=0.218$ \\
\hline Accuracy & $66.0 \%$ & $57.8-70.7 \%$ & $83.0 \%$ & $74.5-89.1 \%$ & $\mathrm{p}=0.006$ \\
\hline Positive predictive value & $86.2 \%$ & $72.0-84.3 \%$ & $85.2 \%$ & $77.3-90.8 \%$ & $\mathrm{p}=0.902$ \\
\hline Negative predictive value & $57.7 \%$ & $52.0-61.0 \%$ & $80.4 \%$ & $81.2-87.0 \%$ & $\mathrm{p}=0.012$ \\
\hline False positivity & $8.9 \%$ & $3.7-18.1 \%$ & $17.8 \%$ & $10.4-25.5 \%$ & $\mathrm{p}=0.218$ \\
\hline False negativity & $54.5 \%$ & $50.3-62.0 \%$ & $16.4 \%$ & $10.8-24.1 \%$ & $\mathrm{p}=0.0001$ \\
\hline
\end{tabular}

Table 2. Statistical comparison of TUS and EUS for diagnosing pathological content of the bile duct.

\begin{tabular}{|l|c|c|c|c|c|}
\hline & TUS & $\begin{array}{c}95 \% \text { confidence } \\
\text { interval }\end{array}$ & EUS & $\begin{array}{c}95 \% \text { confidence } \\
\text { interval }\end{array}$ & $\begin{array}{c}\text { Statistical } \\
\text { significance }\end{array}$ \\
\hline Sensitivity & $32.7 \%$ & $25.1-36.6 \%$ & $87.8 \%$ & $80.9-90.6 \%$ & $\mathrm{p}<0.0001$ \\
\hline Specificity & $94.1 \%$ & $86.9-97.9 \%$ & $96.1 \%$ & $89.5-98.8 \%$ & $\mathrm{p}=0.641$ \\
\hline Accuracy & $64.0 \%$ & $56.6-67.8 \%$ & $92.0 \%$ & $85.3-94.8 \%$ & $\mathrm{p}<0.0001$ \\
\hline Positive predictive value & $84.2 \%$ & $64.7-94.3 \%$ & $95.6 \%$ & $88.1-98.7 \%$ & $\mathrm{p}=0.125$ \\
\hline Negative predictive value & $59.3 \%$ & $54.7-61.6 \%$ & $89.1 \%$ & $83.0-91.6 \%$ & $\mathrm{p}=0.0002$ \\
\hline False positivity & $5.9 \%$ & $2.1-13.1 \%$ & $3.9 \%$ & $1.2-10.5 \%$ & $\mathrm{p}=0.641$ \\
\hline False negativity & $67.3 \%$ & $63.4-74.9 \%$ & $12.2 \%$ & $9.4-19.1 \%$ & $\mathrm{p}<0.0001$ \\
\hline
\end{tabular}

Table 3. Combination of TUS and EUS compared to ERCP. Diagnosis of extrahepatic bile duct dilatation - a positive result in the case of TUS and/or radial EUS positivity.

\begin{tabular}{|l|c|c|}
\hline & & $95 \%$ confidence interval \\
\hline Sensitivity & $90.9 \%$ & $83.3-98.5 \%$ \\
\hline Specificity & $75.6 \%$ & $63.0-88.1 \%$ \\
\hline Accuracy & $84.0 \%$ & $76.8-91.2 \%$ \\
\hline Positive predictive value & $82.0 \%$ & $72.3-91.6 \%$ \\
\hline Negative predictive value & $87.2 \%$ & $76.7-97.7 \%$ \\
\hline False positivity & $24.4 \%$ & $11.9-37.0 \%$ \\
\hline False negativity & $9.1 \%$ & $1.5-16.7 \%$ \\
\hline
\end{tabular}

\section{RESULTS}

In the group of 100 patients, cholestasis was icteric in 66 patients $(66 \%$, mean age in the group $63 \pm 12)$ and anicteric in 34 patients (34\%, mean age in the group $61 \pm 14$ ).

A total of 49 patients (49\%) had other diagnoses than choledocholithiasis - common bile duct stenosis (24 patients), pancreatic cancer (12), chronic pancreatitis (5), tumor of the papilla of Vater (5), pancreatic cysts (2) or acute pancreatitis (1). Of those, $31(63.3 \%)$ were in the icteric cholestatis subgroup and $18(36.7 \%)$ in the anicteric subgroup.

In 37 patients $(37 \%)$, the bile duct was not dilated. Of those, $24(64.9 \%)$ were in the icteric cholestatis subgroup and $13(35.1 \%)$ in the anicteric subgroup. Choledocholithiasis was present in 9 (24.3\%) of them; the remaining 28 (75.7\%) patients were free from choledocholithiasis. 
Table 4. Combination of TUS and EUS compared to ERCP. Diagnosis of extrahepatic bile duct dilatation - a positive result in the case of TUS and radial EUS positivity.

\begin{tabular}{|l|c|c|}
\hline & & $95 \%$ confidence interval \\
\hline Sensitivity & $38.2 \%$ & $25.3-51.0 \%$ \\
\hline Specificity & $97.8 \%$ & $93.5-100 \%$ \\
\hline Accuracy & $65.0 \%$ & $55.7-74.3 \%$ \\
\hline Positive predictive value & $95.5 \%$ & $86.8-100 \%$ \\
\hline Negative predictive value & $56.4 \%$ & $45.4-67.4 \%$ \\
\hline False positivity & $2.2 \%$ & $0.0-6.5 \%$ \\
\hline False negativity & $61.8 \%$ & $49.0-74.7 \%$ \\
\hline
\end{tabular}

Table 5. Combination of TUS and EUS compared to ERCP. Diagnosis of pathological content of the extrahepatic bile duct - a positive result in the case of TUS and/or radial EUS positivity.

\begin{tabular}{|l|c|c|}
\hline & & $95 \%$ confidence interval \\
\hline Sensitivity & $87.8 \%$ & $78.6-96.9 \%$ \\
\hline Specificity & $94.1 \%$ & $87.7-100 \%$ \\
\hline Accuracy & $91.0 \%$ & $85.4-96.6 \%$ \\
\hline Positive predictive value & $93.5 \%$ & $86.3-100 \%$ \\
\hline Negative predictive value & $88.9 \%$ & $80.5-97.3 \%$ \\
\hline False positivity & $5.9 \%$ & $0.0-12.3 \%$ \\
\hline False negativity & $12.2 \%$ & $3.1-21.4 \%$ \\
\hline
\end{tabular}

Table 6. Combination of TUS and EUS compared to ERCP. Diagnosis of pathological content of the extrahepatic bile duct - a positive result in the case of TUS and radial EUS positivity.

\begin{tabular}{|l|c|c|}
\hline & & $95 \%$ confidence interval \\
\hline Sensitivity & $32.7 \%$ & $19.5-45.8 \%$ \\
\hline Specificity & $96.1 \%$ & $90.8-100 \%$ \\
\hline Accuracy & $65.0 \%$ & $55.7-74.3 \%$ \\
\hline Positive predictive value & $88.9 \%$ & $74.4-100 \%$ \\
\hline Negative predictive value & $59.8 \%$ & $49.1-70.4 \%$ \\
\hline False positivity & $3.9 \%$ & $0.0-9.2 \%$ \\
\hline False negativity & $67.3 \%$ & $54.2-80.5 \%$ \\
\hline
\end{tabular}

Complications during and following ERCP were noted in $5(5 \%)$ patients and were as follows: irritation of the pancreas ( 2 cases), bleeding from the papilla of Vater after papilla sphincterotomy (2) and acute pancreatitis (1). No complications were recorded either during or after
EUS which makes this imaging method more beneficial than ERCP.

As for the risk of choledocholithiasis, 22 (22\%) patients were in the moderate-risk group and 78 (78\%) in the high-risk group. None of the patients belonged to the 


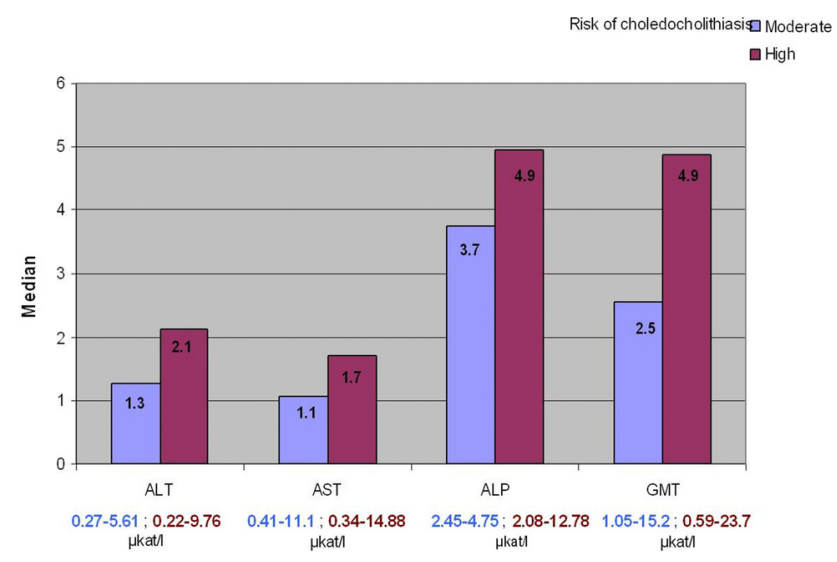

Fig. 1. Complete laboratory results compared to the risk of choledocholithiasis. The graph shows the median of laboratory data. The lowest and the highest values are shown in color.

low-risk group. Lithiasis was confirmed in 6 (27.3\%) patients from the moderate-risk group and in 45 (57.7\%) from the high-risk group. The prevalence of lithiasis was statistically significantly higher in the high-risk group than in the moderate-risk group ( $p=0.012$ ).

Complete laboratory results compared with the risk of choledocholithiasis are summarized in (Fig. 1,2). In the subgroup of patients with a high risk of choledocholithiasis, the median values of individual laboratory markers were higher in all cases.

The comparison of transabdominal ultrasonography and ERCP for diagnosing bile duct dilatation (Fig. 3)

The two examination methods gave simultaneously positive results in 25 (25\%) patients and simultaneously negative results in 41 (41\%) patients; in 34 patients (34\%), the results were not identical. The results are shown in (Table 1).

The comparison of radial EUS and ERCP for diagnosing bile duct dilatation (Fig. 4,5).

The results were simultaneously positive in $46(46 \%)$ patients and simultaneously negative in 37 (37\%) patients examined by the two methods. No agreement was found in $17(17 \%)$ patients. The results are shown in (Table 1).

When diagnosing bile duct dilatation, radial endosonography was significantly more sensitive (84\%) and accurate $(83 \%)$ than transabdominal ultrasonography ( $46 \%$ sensitivity and $66 \%$ accuracy), i.e. $p=0.001$ and $\mathrm{p}=0.006$, respectively. There was no significant difference in the specificity of the two methods $(p=0.218)$.

The comparison of transabdominal ultrasonography and ERCP for diagnosing pathological content of the bile duct.

The two methods yielded simultaneously positive results in $16(16 \%)$ patients and simultaneously negative results in 48 (48\%) patients; in 36 patients (36\%), the results were not identical. The results are summarized in (Table 2).

The comparison of radial EUS and ERCP for diagnosing pathological content of the bile duct. (Fig. 4,5)

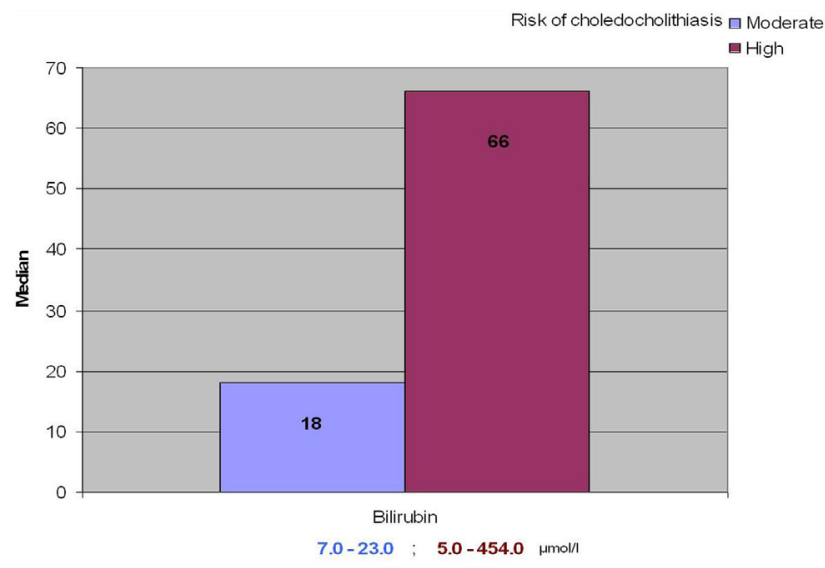

Fig. 2. Complete laboratory results compared to the risk of choledocholithiasis. The graph shows the median of laboratory data. The lowest and the highest values are shown in color.

The results of the two examination methods were simultaneously positive in $43(43 \%)$ patients and simultaneously negative in 49 (49\%) patients. No agreement was found in $8(8 \%)$ patients. The results are shown in (Table 2).

Also when diagnosing pathological content of the bile duct, radial endosonography was statistically significantly more sensitive (88\%) and accurate (92\%) than transabdominal ultrasonography (33\% sensitivity and 64\% accuracy), $\mathrm{p}<0.0001$. In this case too, there was no significant difference in the specificity of the two methods ( $p=0.641)$.

A comparison was performed of TUS together with radial EUS and ERCP. In the first case, a positive finding was defined as one confirmed by at least one of the methods, i.e. TUS or EUS (Table 3,5). In the second case, a positive result was one shown by both methods (Table 4,6 ). Once again, the analyses were made for diagnosing both bile duct dilatation (Table 3,4) and pathological contents of the bile duct (Table 5,6). The results are summarized in the respective tables.

\section{DISCUSSION}

EUS examination is a minimally invasive method providing high-quality images of the biliary tree, with premedication similar to that in ERCP and the incidence of complications equal to that in esophagogastroduodenoscopy. Multicenter studies claim a zero risk of more severe

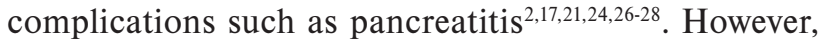
EUS cannot replace ERCP due to unavailable therapeutic procedures.

In addition to the aforementioned advantages of EUS (high sensitivity and specificity, simple performance and interpretation of results, detection of unrecognized microlithiasis, no or minimal complications, absence of radiation), the method is also ideal for use in patients allergic to contrast media or pregnant women. 


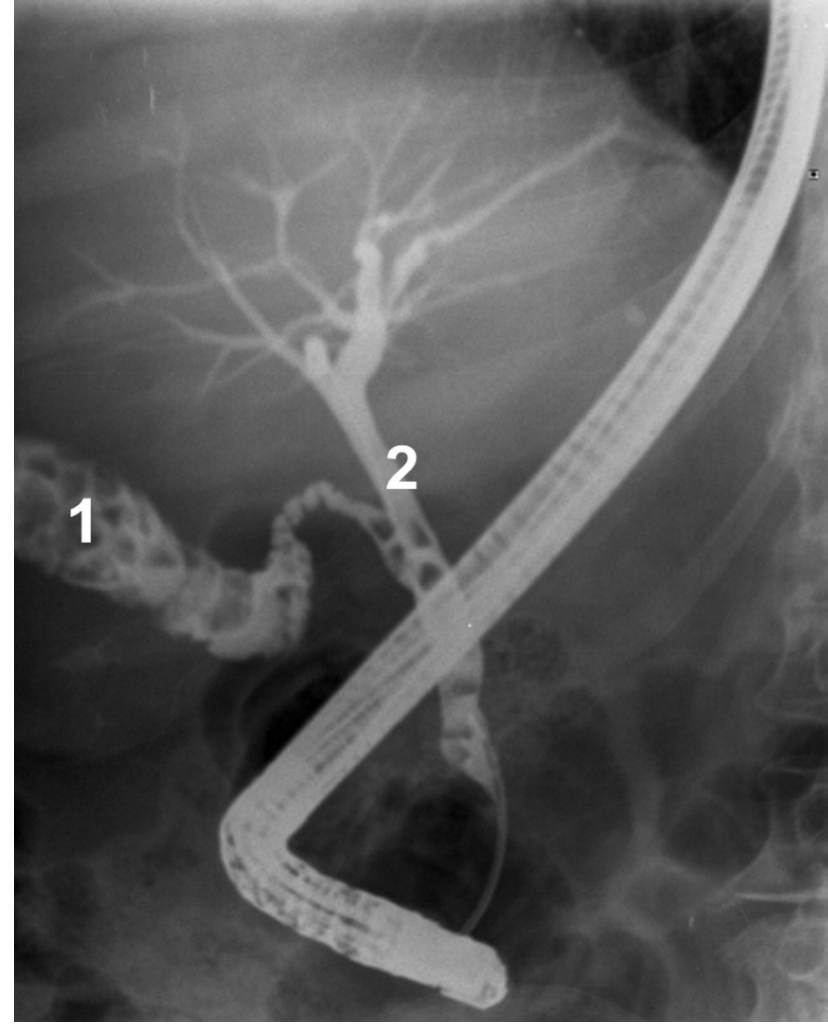

Fig. 3. Skiagram of ERCP examination. 1. Multiple cholecystolithiasis, 2. Multiple choledocholithiasis.

Furthermore, bile duct examination may reveal coexisting pathologies of the pancreaticobiliary region potentially causing biliary obstruction. Apart from choledocholithiasis, these include tumors of the papilla of Vater, pancreatic head cancer, pancreatic cysts and pseudocysts, cholangiocarcinoma or congenital anomalies ${ }^{29}$.

The method is potentially limited by the investigator's practical skills and experience. However, diagnosing gallstones does not require a high level of skills. The existing data show that more than 150 EUS procedures have to be performed under supervision to gain practical experience in all areas of EUS (ref. ${ }^{30,31}$ ).

The presence of gallstones in the common bile duct may be predicted using numerous clinical, laboratory and radiographic criteria ${ }^{32}$. Patients in the low-risk group have normal liver test results, a bile duct diameter of $\leq$ $7 \mathrm{~mm}$ and no history of cholecystolithiasis. In this group, the risk of detecting lithiasis in the common bile duct is $2-3 \%$. The group with a moderate risk of detection of choledocholithiasis includes patients with a history of acute cholangitis or biliary pancreatitis and/or recorded increased liver test values and/or present mild dilatation of the bile duct $(8-10 \mathrm{~mm})$. In this group, the risk of choledocholithiasis is increased to $20-50 \%$. The high-risk group patients have a recent history of episodes of acute cholangitis or pancreatitis, jaundice or doubled levels of ALP and/or bile duct dilatation of $\geq 11 \mathrm{~mm}$. In such cases, the risk of choledocholithiasis is $50-80 \%$. Given this stratification of the risk of choledocholithiasis and potential complications connected with ERCP, EUS should

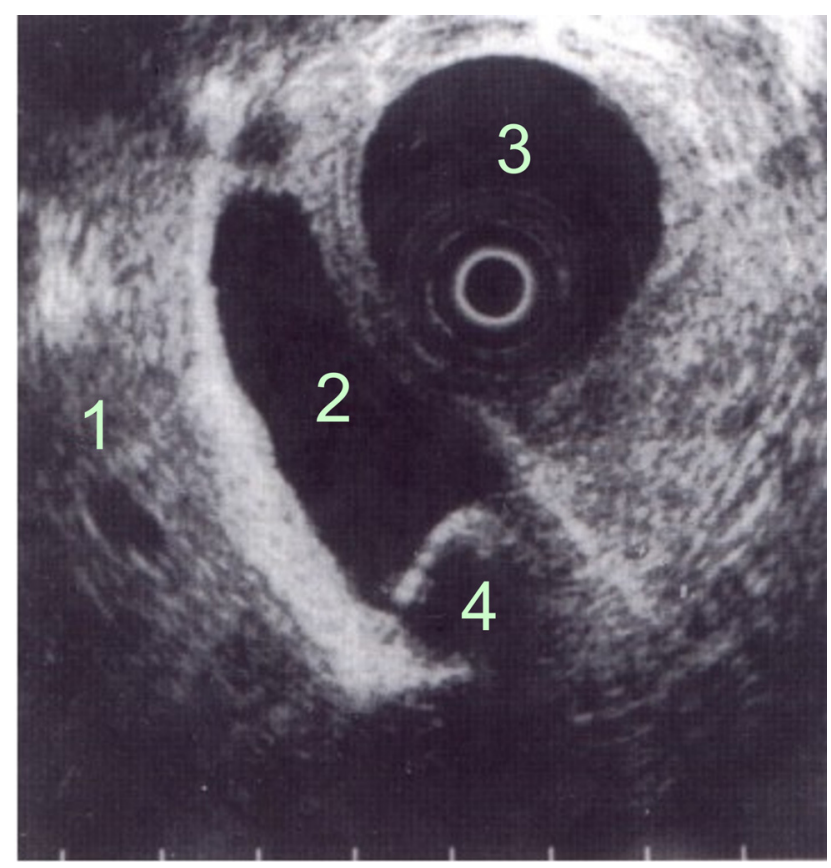

Fig. 4. Endosonographic image of a large common bile duct stone with typical acoustic shadowing visualized from the apex of the duodenal bulb. 1. Liver, 2. Dilated common bile duct, 3. Lumen of the duodenum, 4. Bile stone.

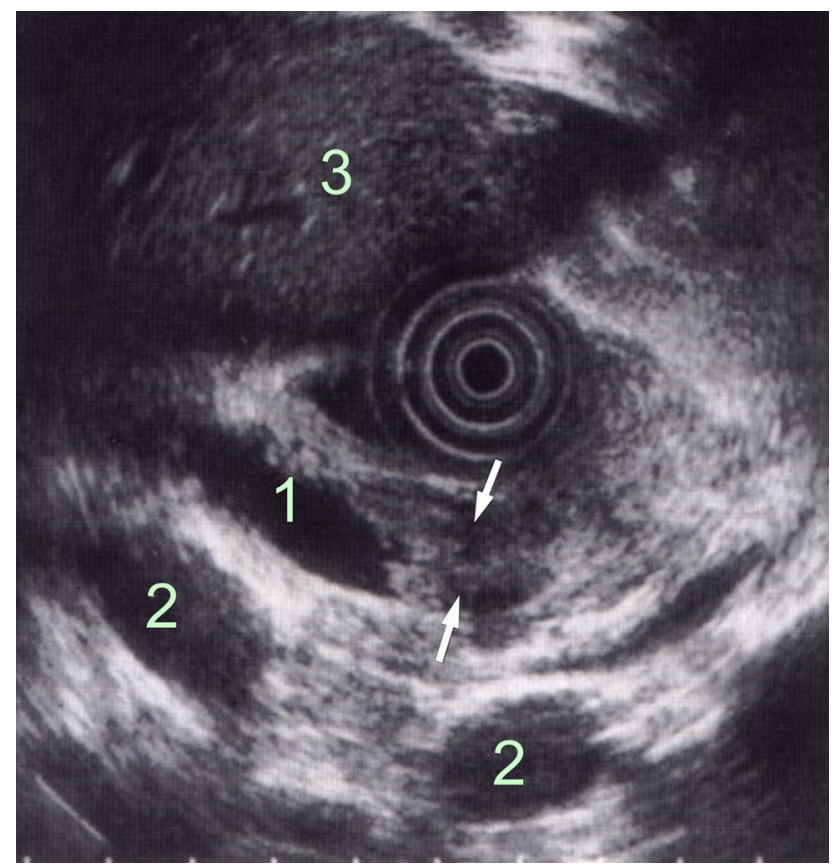

Fig. 5. Endosonographic image of bile duct tumor visualized from the apex of the duodenal bulb. 1. Dilated common bile duct, 2. Portal vein, 3. Liver.

be preferred in patients with a low or moderate risk of choledocholithiasis and ERCP in those with a high risk. Despite the above-mentioned criteria, about one third of potential patients in the high-risk group undergo unnec- 
essary ERCP. This led some authors to a more liberal attitude to the use of radial EUS in patients suspected of choledocholithiasis $^{33}$. This results in significant clinical and economic benefits when compared to the wasteful use of more invasive examination methods.

A similar study concerned with the comparison of radial EUS and ERCP was published by Polkowski et al. ${ }^{34}$. These authors carried out a prospective study in 100 patients divided into two subgroups of 50 individuals. Each subgroup was primarily examined using either endosonography or ERCP. If stones were revealed by radial EUS, therapeutic ERCP was performed and either the unsuccessful examination was repeated or, based on the symptoms, the other examination method was selected (i.e. EUS after unsuccessful ERCP or ERCP after unsuccessful EUS). The risk of moderate to severe complications was not statistically significantly different in the two subgroups. Gallstones were found in 14 patients from the EUS group and in 12 ERCP patients. The overall numbers of diagnostic and therapeutic endoscopy procedures performed during a one-year study period were not significantly differ. The authors concluded that EUS should replace diagnostic ERCP in patients with a moderate risk of choledocholithiasis. EUS should be followed by ERCP selectively in patients with confirmed choledocholithiasis.

Another method that can be used for examining the bile duct is magnetic resonance cholangiography (MRCP), beneficial especially for its noninvasiveness and absence of radiation. Thus, MRCP may be used in patients with a low to moderate risk of choledocholithiasis and with contraindicated endoscopy. However, the equipment is rather expensive and, as in the case of radial EUS, the result depends on the investigator's experience. The resolution of magnetic resonance imaging (MRI) is somewhat lower than that of EUS ( 0.1 vs. $1.5 \mathrm{~mm})$, resulting in lower sensitivity in the detection of small stones. According to the literature, MRI has the sensitivity of $97.5-100 \%$, specificity of $72.7-100 \%$, positive predictive value of $62.5-100 \%$ and negative predictive value of 81.1 $100 \%$ for the detection of bile duct stones ${ }^{35,36}$. In patients with the narrow bile duct and minute stones, the MRI sensitivity drops to $40-60 \%$ (ref. ${ }^{36}$ ).

Finally, we would like to turn the attention to the not insignificant financial burden of these examination methods. This is supported by several articles concerned with detailed analyses of the economic aspects of the use of TUS, EUS, MRCP and ERCP (ref. ${ }^{37}$ ).

\section{CONCLUSION}

For its high sensitivity and specificity, ERCP was considered the standard to which the results of our investigations were compared. In the diagnosis of bile duct dilatation, radial EUS is a method with significantly higher sensitivity and accuracy than transabdominal ultrasonography. When diagnosing pathological content of the bile duct (lithiasis), radial EUS is once again significantly more sensitive and accurate than TUS. On the other hand, the specificity of detecting dilatation and pathological content of the bile duct were not significantly different.

The study of the benefits of EUS in patients with the extrahepatic bile duct obstructed by choledocholithiasis showed $87.8 \%$ sensitivity, $96.1 \%$ specificity and the positive and negative predictive values of $95.6 \%$ and $89.1 \%$, respectively. The results for our group of patients are consistent with those reported in the literature.

Our suggestion is that in patients with a high risk of choledocholithiasis, conventional therapeutic ERCP should be the method of choice. However, if the risk is mild to moderate, EUS should be preferred to ERCP or elective cholecystectomy.

\section{ACKNOWLEDGEMENT}

The work was supported by IGA MZ ČR NT 11023 grant. The study was carried out during routine practice at the clinic of the above mentioned coauthors in patients with pancreatic-biliary diseases.

\section{REFERENCES}

1. Di Nardo R, Urbano D, Drudi FM, Chianta GL, Tortora A, De Simone P, Rossi P. Ultrasonography in the preoperative assessment of candidates for laparoscopic cholecystectomy: examination technique and results. Radiol Med 1996;92:605-9.

2. Sugiyama M, Atomi Y. Endoscopic ultrasonography for diagnosing choledocholithiasis: a prospective comparative study with ultrasonography and computed tomography. Gastrointest Endosc 1997;45:143-6.

3. Chak A, Hawes RH, Cooper GS, Hoffman B, Catalano MF, Wong RC, Herbener TE, Sivak MV Jr. Prospective assessment of the utility of EUS in the evaluation of gallstone pancreatitis. Gastrointest Endosc 1999;49:599-604.

4. Pickuth D, Spielmann RP. Detection of choledocholithiasis: comparison of unenhanced spiral CT, US, and ERCP. Hepatogastroenterol 2000;47:1514-7.

5. Stott MA, Farrands PA, Guyer PB, Dewbury KC, Browning JJ, Sutton R. Ultrasound of the common bile duct in patients undergoing cholecystectomy. J Clin Ultrasound 1991;19:73-6.

6. Vilgrain V, Palazzo L. Choledocholithiasis: role of US and endoscopic ultrasound. Abdom Imaging 2001;26:7-17.

7. Tham TC, Collins JS, Watson RG, Ellis PK, McIlrath EM. Diagnosis of common bile duct stones by intravenous cholangiography: prediction by ultrasound and liver function tests compared with endoscopic retrograde cholangiography. Gastrointest Endosc 1996;44:158-63.

8. Cotton PB, Lehman G, Vennes J, Geenen JE, Russell RC, Meyers WC, Liguory C, Nickl N. Endoscopic sphincterotomy complications and their management: an attempt at consensus. Gastrointest Endosc 1991;37:383-93.

9. Cheng CL, Sherman S, Watkins JL, Barnett J, Freeman M, Geenen J, Ryan M, Parker H, Frakes JT, Fogel EL, Silverman WB, Dua KS, Aliperti G, Yakshe P, Uzer M, Jones W, Goff J, Lazzell-Pannell L, Rashdan A, Temkit M, Lehman GA. Risk factors for post-ERCP pancreatitis: a prospective multicenter study. Am J Gastroenterol 2006;101:139-47.

10. Shimutzi S, Tada M, Kawai K. Diagnostic ERCP. Endoscopy 1994;26:88-92.

11. Prat F, Edery J, Meduri B, Chiche R, Ayoun C, Bodart M, Grange D, Loison F, Nedelec P, Sbai-Idrissi MS, Valverde A, Vergeau B. Early EUS of the bile duct before endoscopic sphincterotomy for acute biliary pancreatitis. Gastrointest Endosc 2001;54:724-9. 
12. Freeman ML, DiSario JA, Nelson DB, Fennerty MB, Lee JG, Bjorkman DJ, Overby CS, Aas J, Ryan ME, Bochna GS, Shaw MJ, Snady HW, Erickson RV, Moore JP, Roel JP. Risk factors for postERCP pancreatitis: a prospective, multicenter study. Gastrointest Endosc 2001;54:425-34.

13. Christensen M, Matzen P, Schulze S, Rosenberg J. Complications of ERCP: a prospective study. Gastrointest Endosc 2004;60:721-31.

14. Christoforidis E, Goulimaris I, Kanellos I, Tsalis K, Demetriades C, Betsis D. Post-ERCP pancreatitis and hyperamylasemia: patientrelated and operative risk factors. Endoscopy 2002;34:286-92.

15. Masci E, Toti G, Mariani A, Curioni S, Lomazzi A, Dinelli M, Minoli G, Crosta C, Comin U, Fertitta A, Prada A, Passoni GR, Testoni PA. Complications of diagnostic and therapeutic ERCP: a prospective multicenter study. Am J Gastroenterol 2001;96:41723.

16. Petelin JB, Pruett CS. Common bile duct stones. In Cameron JL, ed. Current Surgical Therapy. Philadelphia: Elsevier Mosby, 2004:392-9.

17. Amouyal P, Amouyal G, Lévy P, Tuzet S, Palazzo L, Vilgrain V, Gayet B, Belghiti J, Fékété F, Bernades P. Diagnosis of choledocholithiasis by endoscopic ultrasonography. Gastroenterology 1994; 106:1062-7.

18. Kohut M, Nowakowska-Duława E, Marek T, Kaczor R, Nowak A Accuracy of linear endoscopic ultrasonography in the evaluation of patients with suspected common bile duct stones. Endoscopy 2002:34:299-303.

19. Lachter J, Rubin A, Shiller M, Lavy A, Yasin K, Suissa A, Reshef R. Linear EUS for bile duct stones. Gastrointest Endosc 2000;51:51-4.

20. Napoléon B, Dumortier J, Keriven-Souquet O, Pujol B, Ponchon T, Souquet JC. Do normal findings at biliary endoscopic ultrasonography obviate the need for endoscopic retrograde cholangiography in patients with suspicion of common bile duct stone? A prospective follow-up study of 238 patients. Endoscopy 2003;35:411-5.

21. Norton SA, Alderson D. Prospective comparison of endoscopic ultrasonography and endoscopic retrograde cholangiopancreatoghraphy in the detection of bile duct stones. Br J Surg 1997;84:1366-9.

22. Dancygier H, Nattermann C. The role of endoscopic ultrasonography in biliary tract disease: obstructive jaundice. Endoscopy 1994;26:800-2.

23. Palazzo L, Girollet PP, Salmeron M, Silvain C, Roseau G, Canard JM, Chaussade S, Couturier D, Paolaggi JA. Value of endoscopic ultrasonography in the diagnosis of common bile duct stones: comparison with surgical exploration and ERCP. Gastrointest Endosc 1995;42:225-31.

24. Prat F, Amouyal G, Amouyal P, Pelletier G, Fritsch J, Choury AD, Buffet C, Etienne JP. Prospective controlled study of endoscopic ultrasonography and endoscopic retrograde cholangiography in patients with suspected common-bileduct lithiasis. Lancet 1996;347:75-9.
25. Rathod V, Maydeo A. How safe in endoscope ultrasound? A retrospective analysis of complications encountered during diagnosis and interventional endosonography in large individual series of 3006 patients from India [abstract]. Gastrointest Endosc 2002;56(Suppl):S144.

26. Amouyal P, Palazzo L, Amouyal G, Ponsot P, Mompoint D, Vilgrain V, Gayet B, Fléjou JF, Paolaggi JA. Endosonography: promising method for diagnosis of extrahepatic cholestasis. Lancet 1989;18:1195-8.

27. Canto MI, Chak A, Stellato T, Sivak MV Jr. Endoscopic ultrasonography versus cholangiography for the diagnosis of choledocholithiasis. Gastrointest Endosc 1998;47:439-48.

28. Shim CS, Joo JH, Park CW, Kim YS, Lee JS, Lee MS, Hwang SG. Effectiveness of endoscopic ultrasonography in the diagnosis of choledocholithiasis prior to laparoscopic cholecystectomy. Endoscopy 1995;27:428-32.

29. Rösch T, Hofrichter K, Frimberger E, Meining A, Born P, Weigert N, Allescher HD, Classen M, Barbur M, Schenck U, Werner M. ERCP or EUS for tissue diagnosis of biliary strictures? A prospective comparative study. Gastrointest Endosc 2004;60:390-6.

30. Palazzo L, Girollet PP, Salmeron M, Silvain C, Roseau G, Canard JM, Chaussade S, Couturier D, Paolaggi JA. Value of endoscopic ultrasonography in the diagnosis of common bile duct stones: comparison with surgical exploration and ERCP. Gastrointest Endosc 1995;42:225-31.

31. Palazzo L, O'Toole D. EUS in common bile duct stones. Gastrointest Endosc 2002;56:49-58.

32. Ang TL, Teo EK, Fock KM. Endosonography- vs. endoscopic retrograde cholangiopancreatography-based strategies in the evaluation of suspected common bile duct stones in patients with normal transabdominal imaging. Aliment Pharmacol Ther 2007;26:116370 .

33. Buscarini E, Tansini P, Vallisa D, Zambelli A, Buscarini L. EUS for suspected choledocholithiasis: do benefits outweigh costs? A prospective, controlled study. Gastrointest Endosc 2003;57:510-8.

34. Polkowski M, Regula J, Tilszer A, Butruk E. Endoscopic ultrasound versus retrograde cholangiography for patients with intermediate probability of bile duct stones: a randomized trial comparing two management strategies. Endoscopy 2007;39:296-303.

35. Materne R, Van Beers BE, Gigot JF, Jamart J, Geubel A, Pringot J, Deprez P. Extrahepatic biliary obstruction: magnetic resonance imaging compared with endoscopic ultrasonography. Endoscopy 2000;32:3-9.

36. Mendler MH, Bouillet P, Sautereau D. Value of MR cholangiography in the diagnosis of obstructive diseases of the biliary tree: a study of 58 cases. Am J Gastroenterol 1998;93:2482-90.

37. Rösch T, Meining A, Frühmorgen S, Zillinger C, Schusdziarra V, Hellerhoff K, Classen M, Helmberger H. A prospective comparison of the diagnostic accuracy of ERCP, MRCP, CT, and EUS in biliary strictures. Gastrointest Endosc 2002;55:870-6. 